\title{
Study of the true tensile stress-strain diagram of plain concrete with real size aggregate; need for and design of a large Hopkinson bar bundle
}

C. Albertini and M. Montagnani

Commission of the European Communities, Joint Research Centre, Institute of Safety Technology, 21020 Ispra (Varese), Italy

\begin{abstract}
Resumé: L'idée est discutée d'employer deux grands faisceaux de barres d'Hopkinson, disposées de façon spéculaire, pour l'observation de la distribution instantanée de la contrainte et de la déformation sur la section résistante des grandes éprouvettes de béton, chargées en dynamique rapide.
\end{abstract}

\begin{abstract}
The idea is discussed of using two specular bundles of Hopkinson's bars for the experimental observation of the instantaneous distribution of stress and strain over the cross-section of large concrete specimens with real size aggregate, subjected to high loading rates.
\end{abstract}

\section{INTRODUCTION}

The true stress-strain diagram at high loading rate of plain concrete is of basic importance for the assessment of the resistance of civil engineering structures against accidental loadings like those provoked by earthquakes and explosions.

Normally, Hopkinson bars for steel have a diameter of 10-20 mm, [1] [2], which is sufficient to load small specimens representative of fine-grained materials like steel. In the last decade, two research groups (Kormeling et al., [3]), (Malvern et al., [4] increased the bar diameter to 60 and $75 \mathrm{~mm}$, respectively, in order to load representative plain concrete specimens having an aggregate of 8-10 mm size; we have also heard of a $100 \mathrm{~mm}$ diameter bar used in the USA by Ross.

The Hopkinson bar system developed in our research differs from the two systems mentioned above in two ways:

- the mechanical pulse is generated by the elastic energy stored in a prestressed bar (not by an impacting projectile) [5];

the bar shape is a square of $6 \times 6 \mathrm{~cm}$ instead of being round, of small transverse dimension in comparison with the wavelength of the applied stress pulse $(200 \mathrm{~cm})$. The propagation dispersion of stress pulses in square bars is similar to that of cylindrical bars [6].

\section{EXPERIMENTAL EQUIPMENT}

The Hopkinson bar developed in our laboratory for tensile tests of plain concrete is sketched in Figure 1. As a first operation, a hydraulic actuator prestresses only the steel bar up to its elastic 
limit because of the frictional action of a blocking device. The successive operation is the controlled rupture of a brittle intermediate piece of the blocking device, which gives rise to a tensile mechanical pulse of rectangular shape, propagating along the first aluminium bar, specimen and the second aluminium bar; the generated tensile mechanical pulse has a constant amplitude and a duration of $\sim 92010^{-6} \mathrm{~s}$ because the prestressed bar has a length of $2300 \mathrm{~mm}$.

The plain concrete specimen has the same cross-section $(6 \times 6 \mathrm{~cm})$ as the aluminium bars, to which it is glued with an epoxy resin. Aluminium was chosen as the bar material because of its transverse modulus, which is not far from that of plain concrete. This last fact, together with some fine longitudinal cuts on the ends of the aluminium bars glued to the specimen, minimizes the constraint to transverse deformation of the concrete specimen. A first strain gauge station on the incident bar measures the incident pulse $\epsilon_{\mathrm{I}}$ and the reflected pulse $\epsilon_{\mathrm{R}}$. A second strain gauge station on the transmitted bar measures the pulse $\epsilon_{T}$ transmitted through the specimen. The distance of both the strain gauge stations from the specimen is $700 \mathrm{~mm}$; therefore after $\sim 28010^{-6} \mathrm{~s}$ the strain gauge station on the incident bar gives a measurement of the reflected pulse $\epsilon_{\mathrm{R}}$ obtained from the difference between the amplitude of the incident pulse $\epsilon_{\mathrm{I}}$, measured before the time of $28010^{-6} \mathrm{~s}$, and the actual measurement of the strain gauge. From Figure 2 it can be seen that before the time of $28010^{-6} \mathrm{~s}$ the amplitude of the incident pulse shows very small oscillations, of the order of \pm 2 percent, and therefore the reflected pulse is measured with an accuracy of the same order. The average instantaneous values of the stress and strain of the concrete, assuming uniaxial wave propagation and homogeneous stress distribution in the specimen, are obtained by the following equations:

$$
\sigma(t)=\frac{A E_{\epsilon_{T}}(t)}{A_{0}}
$$

where: $A=$ cross-section of the aluminium bar,

$A_{0}=$ cross-section of the concrete specimen,

$\mathrm{E}=$ Young modulus of aluminium

$\mathrm{t}=$ time

and:

$$
\epsilon(\mathrm{t})=\frac{2 \mathrm{C}}{\mathrm{L}_{\mathrm{o}}} \int_{0}^{\mathrm{t}} \epsilon_{\mathrm{R}}(\mathrm{t}) \mathrm{dt}
$$

where: $\mathrm{C}$ = elastic wave speed in aluminium,

$\mathbf{L}_{\mathrm{o}}=$ length of the concrete specimen,

The strain of the concrete specimen is also measured by strain gauges directly glued on the specimen (Figure 1). A record of the measurements given by the strain gauges glued on the bars and on the specimens is given in Figure 2.

\section{PLAIN CONCRETE COMPOSITION AND SPECIMENS}

The plain concrete composition was the following:

- water/cement ratio 0.5

- \% sand $(0.3 \mathrm{~mm}) \quad 60$

- aggregate quantity $1700 \mathrm{Kg} / \mathrm{m}^{3}$

- maximum aggregate size $10 \mathrm{~mm}$
- cement type R425

- \% gravel (3-10 mm) 40

- cement quantity $\quad 375 \mathrm{Kg} / \mathrm{m}^{3}$ 


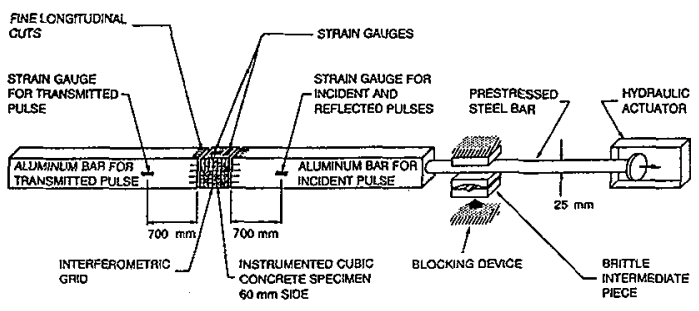

Figure 1: Hopkinson bar for dynamic tension testing of plain concrete.

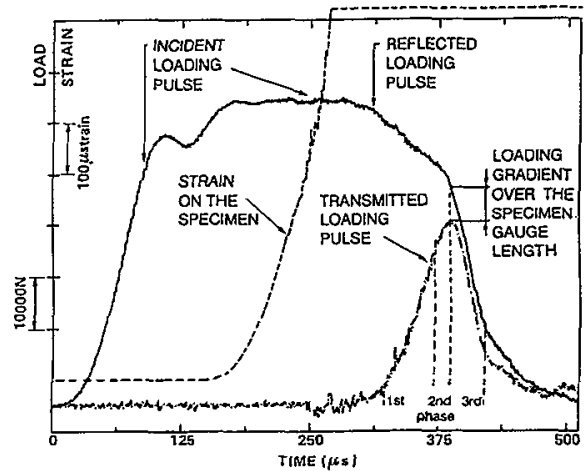

Figure 2: Record of a tensile test on a concrete specimen by a modified Hopkinson bar.

The specimens had a square cross-section of $6 \times 6 \mathrm{~cm}$ and the following lengths: $3,5,7,10,12$ and $15 \mathrm{~cm}$. The plain concrete with this aggregate size is normally defined as "micro concrete" because the aggregate size normally used in real civil structures is larger $(>25 \mathrm{~mm})$.

\section{RESULTS AND DISCUSSION OF MICROCONCRETE TESTING}

The stress strain curves in tension of plain concrete at strain rates of $6 \times 10^{-7}$ and $2.5 \mathrm{~s}^{-1}$ (loading rate $10^{6} \mathrm{~N} / \mathrm{mm}^{2} \mathrm{~s}$ ) were determined following two methods:

a) using the Hopkinson bar formulae (1) and (2) giving the stress and strain values at each instant of the test from the records of transmitted and reflected pulses, respectively;

b) using the Hopkinson bar formula (1) to calculate the stress and the direct measurement of the strain on the specimen by means of the glued electrical strain gauge.

The two measurement methods gave results which are in good agreement as far as the rising branch of the stress strain curve is concerned (Figure 3), while the falling branch of the curve could be measured only by the Hopkinson bar formulae (method a) because the strain gauge on the specimen broke when the highest strength was reached in the specimen. The results obtained at low and high strain rate with specimens of different lengths are shown in Figure 4, where we observe that:

- at high strain rate the ultimate tensile strength is about 2.5 times the strength at low strain rate;

- at high strain rate the strain at the ultimate tensile strength is about twice as large as that at low strain rate.

The explanation of the two phenomena may be based on the fact that, in dynamics, the increase of the load is so fast that all the components of the mix contribute to the resistance against the external load because there is not sufficient time for the external load to follow the path of highest weakness through the mix. In fact, observation of the fracture surfaces of the specimens loaded in dynamic conditions, which were usually normal to the load direction, showed a large amount of fractured coarse aggregate, as was also observed by Kormeling et al. [3].

Observing the records of the incident, reflected and transmitted pulses versus time of Figure 2, we can distinguish three phases:

$1^{\text {st }) ~ t r a n s m i t t e d ~ p u l s e ~ r i s i n g ~ w i t h ~ a ~ r o u g h l y ~ c o n s t a n t ~ s l o p e ~ a n d ~ r e f l e c t e d ~ p u l s e ~ a l s o ~ i n c r e a s i n g ~}$ with a constant slope;

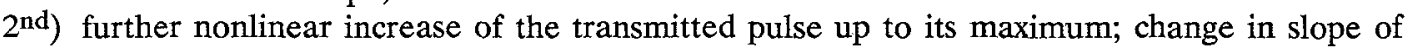
the reflected pulse;

$3^{\text {rd }) ~ s h a r p ~ d e c r e a s e ~ o f ~ t h e ~ t r a n s m i t t e d ~ p u l s e ~ a n d ~ i n c r e a s e ~ o f ~ t h e ~ r e f l e c t e d ~ p u l s e ~ w i t h ~ t h e ~ s a m e ~}$ constant slope - sharper than during phase 1. 


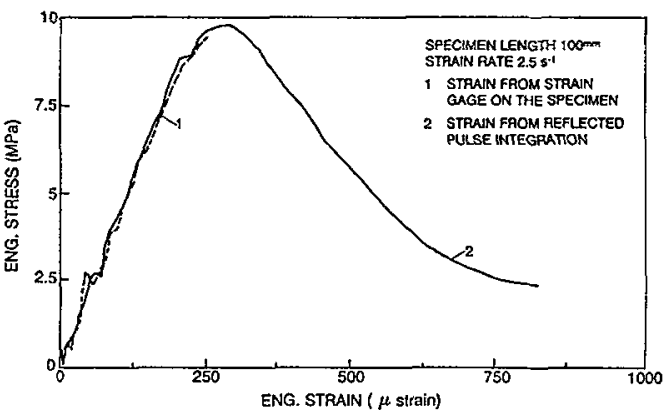

Figure 3: Stress strain curves of micro concrete by Hopkinson bar measurements and by strain gauge measurement.

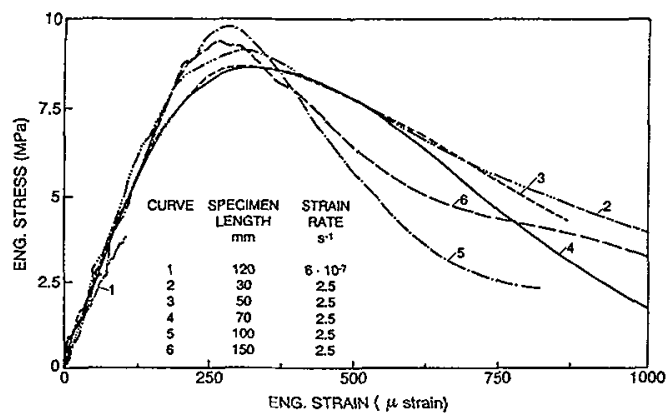

Figure 4: Stress strain curves by Hopkinson bar measurements of micro concrete specimens of different lengths.

The transmitted and reflected pulses of the first phase give rise to the nearly linear part of the stress strain diagram of Figure 4, where the material could be considered elastic. The transmitted and reflected pulses of the second phase give the highly nonlinear upper part of the stress strain diagram of Figure 4; during this phase, microcracks probably develop and coalesce (see also Kormeling et al., [3]). The descending branch of the stress strain diagram of Figure 4 is obtained from the third phase, transmitted and reflected pulses. During this phase it is assumed that macrocracks propagate through the whole thickness of the specimen.

We have observed that the duration of the third phase has a nearly constant value of about $30 \mu \mathrm{s}$, resulting in a high crack propagation speed. Therefore, the simplification of using the initial crosssection and the initial gauge length is too rough for the calculation of the stress and strain of the descending part of the diagrams of Figure 4.

From the observation of the stress-strain diagrams of microconcrete (Figure 4) it follows that:

- the main differences in the stress-strain diagrams concern the softening branch characterized by crack propagation which is strongly influenced by aggregate size;

- a correct estimate of the softening branch needs a measurement of the true resisting crosssection and of the strain of the material volume bearing the load during crack propagation;

- the loading gradient over the specimen gauge length increasing up to $150 \mathrm{~mm}$ was of minor importance (see Figure 2).

\section{THE HOPKINSON BAR BUNDLE EQUIPMENT}

From these observations, it was decided to test large concrete specimens (cube with $20 \mathrm{~cm}$ side) with real size aggregate, developing special equipment for the correct characterization of the softening branch of the stress-strain diagram which is very important for the evaluation of the energy absorption capability of the real material used in civil engineering structures.

The special equipment is sketched in Figure 5 and consists of:

- a hydropneumatic head, a prestressed steel bar and a blocking device;

- input and output Hopkinson's bars subdivided into two specular bundles of elementary Hopkinson's bars.

The equipment can be used in a very large range of loading rates, typical of static, earthquake and impact loadings, obtained by a specific loading application mode.

The static and low loading rates can be realized by the direct action of the hydropneumatic head on the specimen, excluding the blocking device.

The medium and high loading rates will be realized by using the device as a Hopkinson's bar. In this case elastic energy is stored in the steel bar by prestressing it with the hydropneumatic head.

Before beginning the test, the load is supported by the blocking device. 


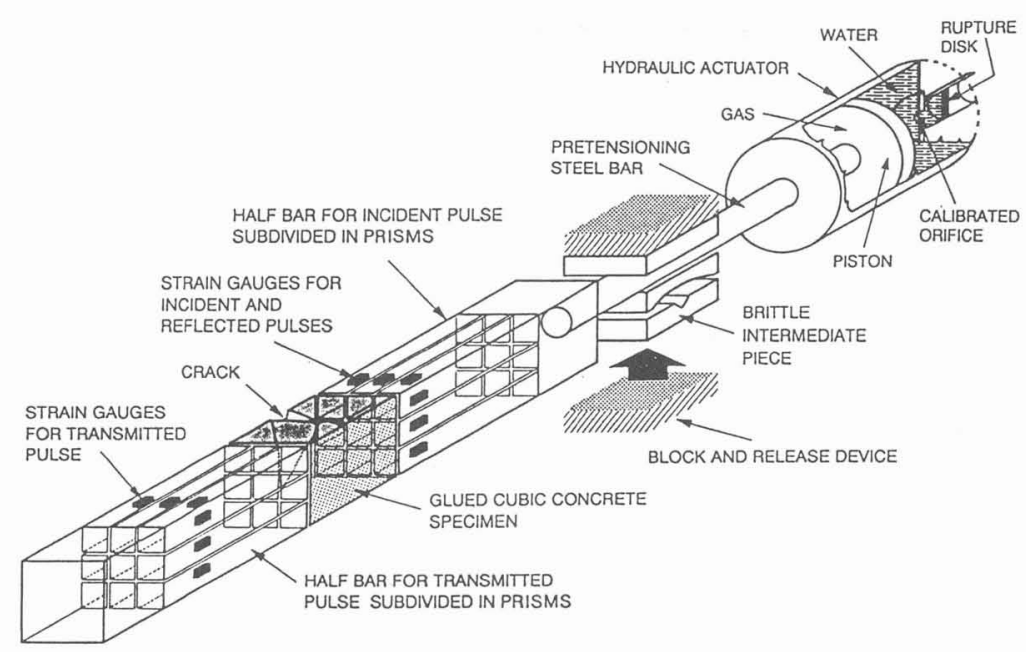

Figure 5 - Bundle Hopkinson Bar for dynamic tension testing of plain concrete.

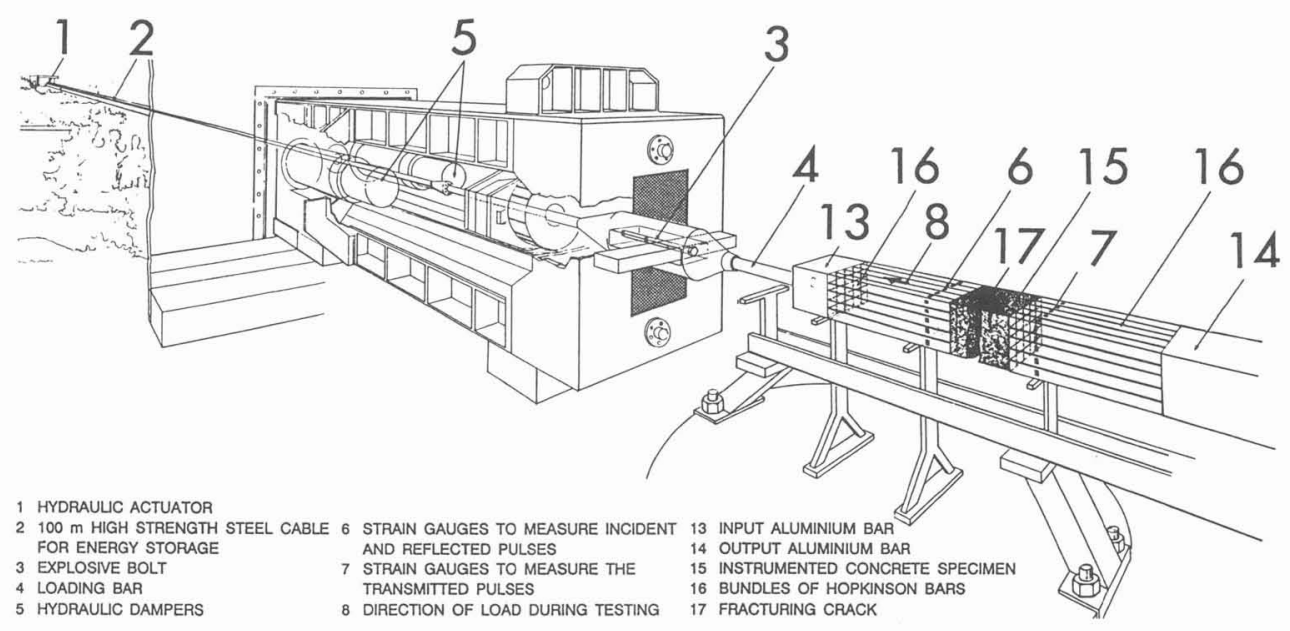

Figure 6 - Tension test of large concrete specimens with crack propagation measurement.

The test begins by deactivation of the blocking device, which gives rise to a pulse with high loading rate propagating along the bundle of the input bars, the specimen and the bundle of the output bars.

During the crack propagation phase each pair of specular bars of the Hopkinson's bar bundles, which is individually instrumented with strain gauges (Figure 5), measures the incident, reflected and transmitted pulses $\epsilon_{\mathbf{I}}, \epsilon_{\mathbf{R}}, \epsilon_{\mathbf{T}}$, concerning only the portion of the specimen cross-section facing the cross-section of the pair of bars of the bundle.

In more detail, during the fracturing process each pair of specular bars of the bundles will be in one of the following physical situations:

1. Facing an uncracked portion of the specimen cross-section, therefore measuring a small reflected pulse $\epsilon \mathbf{R}$ and a large transmitted pulse $\epsilon_{\mathbf{T}}$.

2. Facing a cracked portion of the specimen cross-section, therefore measuring a reflected pulse ${ }^{\epsilon} \mathbf{R}$ of equal amplitude and of opposite sign to the incident pulse $\epsilon_{\mathbf{I}}$, while the correlated transmitted pulse decreases to $\epsilon_{\mathrm{T}}=0$. 
3. Facing a semi-cracked portion of the specimen cross-section, therefore in a measurement situation of $\epsilon_{\mathrm{R}}$ and $\epsilon_{\mathrm{T}}$ in between situations 1 and 2 .

By means of the Hopkinson's bar bundle it is therefore possible to measure moment by moment:

- the true resisting cross-section;

- the true material volume under strain;

- the crack propagation path;

- the crack propagation speed.

These parameters allow a reconstruction of the true stress strain diagram of the material up to complete separation of the specimen into two halves.

The Hopkinson's bar bundles were constructed using two square aluminium bars of $20 \mathrm{~cm}$ side subdivided by electroerosion into 25 pairs of specular bars individually instrumented with strain gauge stations; the two bundles have been installed in the Large Dynamic Testing Facility [7] of the Joint Research Centre as shown in Figure 6, which generates and sends a loading pulse linearly increasing up to a maximum of $2.5 \mathrm{MN}$ into the bundle equipment for the testing of $20 \mathrm{~cm}$ side cubic specimens of plain concrete with real size aggregate $(25-40 \mathrm{~mm}$ size).

\section{ACKNOWLEDGEMENTS}

The authors are grateful to Professor Luigi Cedolin of Milan Polytechnic for helpful discussions and the preparation of the specimens, and to the LDTF staff of JRC (Mrs. E. Blery, A. del Grande, C. Delzano, M. Murarotto, E. Pizzinato, G.L. Prosdocimi, A. Rodis and W. Schnabel).

\section{REFERENCES}

[1] Davies, R.M., A Critical Study of the Hopkinson Pressure Bar, Phil. Trans. Roy. Soc., London, Ser. A, (1948) 240-375.

[2] Lindholm, U.S., High Strain Rate Tests, Technique of Metals Research (J. Wiley, 1971), Vol. 5, Part. 1.

[3] Kormeling, H.A., Zielinski, A.J., Reinhardt, H.W., Report No. 5-80-3, Delft University of Technology, Stevin Laboratory (1980).

[4] Malvern, L.E., Tang, T., Jenkins, D.A., Gong, J.C., Dynamic Compressive Strength of Cementitious Materials, Materials Research Society Symposium, (1986) Vol. 64, 119-138.

[5] Albertini, C., Montagnani, M., Testing Techniques Based on the Split Hopkinson Bar (Institute of Physics, London, 1974) Conf. Ser. No. 21, 22-31.

[6] Kolsky, H., Stress Waves in Solids (Clarendon Press, 1953) 74-75.

[7] Albertini, C., Montagnani, M., Testing Techniques in Dynamic Biaxial Loading, (Institute of Physics, London, 1979). Conf. Ser. No. 47, 25-34. 